\title{
Tessituras entre concepções, curricularização e avaliação da extensão universitária na formação do estudante
}

\author{
Tests between conceptions, curriculation and evaluation of university extension \\ in student training
}

Kátia Curado Silva*

Andréa Kochhann **

\section{Resumo}

Este artigo trata das concepções de extensão universitária na formação do estudante, da curricularização dessas atividades no processo formativo e da avaliação das ações extensionistas. Defende-se que as ações extensionistas influenciam na formação do estudante. Dessarte, é importante compreender qual concepção as atividades carregam e como ocorre seu movimento de avaliação, visto que estão em processo de validação curricular. A metodologia adotada foi qualitativa e bibliográfica, embasada no Plano Nacional de Educação (BRASIL, 2001a, 2014), no Plano Nacional de Extensão Universitária (BRASIL, 2001b, 2011), no Fórum dos Pró-Reitores de Extensão das Universidades Públicas Brasileiras (FORPROEX, 2001, 2012), no Ofício Circular MEC/Sesu n. 263 (BRASIL, 1994 apud REIS, 1996), em Reis (1993, 1995, 1996), entre outros. A tessitura entre a extensão e o processo formativo passa pela compreensão de que as atividades não podem ser de prestação de serviços e assistencialismo, mas acadêmicas, visando à transformação do real. A participação em projetos e programas de extensão deve compor, no mínimo, $10 \%$ dos créditos totais do currículo do estudante, como processo indissociável da pesquisa e do ensino. O acompanhamento e a avaliação das ações extensionistas devem ocorrer seguindo os critérios de indissociabilidade, interdisciplinaridade, interprofissionalidade, produção acadêmica, dialogicidade, transformação social e impacto na formação do estudante, estabelecidos pelo Forproex.

Palavras-chave: Avaliação. Concepção. Curricularização. Extensão. Formação.

\section{Abstract}

This article deals with the conceptions of university extension in student training, curricularisation of these activities in the formative process and evaluation of extensionist actions. We defend that the extensionist actions influence the formation of the student. Therefore, it is important to understand the conception that the activities carry and how the evaluation movement occurs, since they are in the process of curricular validation. The methodology of this article was qualitative and bibliographical, based on National Education Plan (BRASIL, 2001a, 2014), National Extension Plan (BRASIL, 2001b, 2011), Forum of Pro-Rectors of Extension of Brazilian Public Universities (2001, 2012), Circular Letter MEC/SESU 263/1994 (BRASIL, 1994 apud REIS, 1996), Reis (1993, 1995, 1996), and others. The tessitura between the extension and the formative process permeates by understanding that the activities can not be of service provision and assistance, but academic aiming at the transformation of the real. Participation in extension projects and programs should comprise the student's curriculum of at least $10 \%$ of the total credits of the course, as an inseparable process of research and teaching. The monitoring and evaluation of the extensionist actions must follow the criteria of Forum of Pro-Rectors of Extension of Brazilian Public Universities, the indissociability, interdisciplinarity, interprofessionality, academic production, dialogue, social transformation and impact on student training.

Keywords: Conception. Curriculation. Evaluation. Extension. Formation.

Recebido em 27/03/2018 - Aprovado em 20/06/2018

http://dx.doi.org/10.5335/rep.v25i3.8572

Doutora em Educação pela UFG e pós-doutoramento na Unicamp. Docente da UnB. Coordenadora do Grupo de Estudos e Pesquisa em Formação e Atuação de Professor/Pedagogo (Gepfape). E-mail: katia.curado@unb.br

Doutoranda em Educação na UnB. Docente da Universidade Estadual de Goiás. Coordenadora do Grupo de Estudos em Formação de Professores e Interdisciplinaridade (Gefopi). E-mail: andreakochhann@yahoo.com.br 


\section{Introdução}

A escrita deste artigo surgiu de inquietações em relação à extensão universitária nos cursos de formação de professores, construídas no decorrer dos anos de coordenação de um grupo de estudos de formação de professores, o que fomentou o estudo sobre a formação de professores delimitada nas ações extensionistas enquanto variados espaços formativos, que podem contribuir para a formação do estudante no processo inicial ou continuado.

Dialogar sobre a formação do estudante aliada à extensão universitária passa a ser um desafio, visto nosso engajamento com o ensino superior, pois entendemos a importância de uma práxis crítico-emancipadora para essa formação e percebemos, ao participar de eventos e realizar leituras sobre a temática, que essa situação não tem acontecido. A defesa que fazemos é que a formação de professores seja ancorada nos princípios da crítica e da emancipação, e a universidade, principalmente a pública, tenha como missão a formação com esses princípios e esteja alicerçada na indissociabilidade pesquisa, ensino e extensão. Para compreendermos a formação do estudante levando em consideração a extensão universitária, é preciso analisar suas concepções, a curricularização e seu processo avaliativo.

A pesquisa que culminou no presente artigo foi qualitativa e bibliográfica. Foi qualitativa no sentido de que primamos pela compreensão dos dados de forma qualitativa, considerando a totalidade, a contradição e a mediação. Foi bibliográfica, pois embasamo-nos em livros e documentos, como o Plano Nacional de Educação (PNE) (BRASIL, 2001a, 2014), o Plano Nacional de Extensão Universitária (PNEU) (BRASIL, 2001b, 2011), publicações do Fórum dos Pró-Reitores de Extensão das Universidades Públicas Brasileiras (Forproex) (2001, 2012), o Ofício Circular MEC/Sesu n. 263 (BRASIL, 1994 apud REIS, 1996) e as considerações de Reis (1993, 1995, 1996), entre outros autores. A tessitura entre as atividades de extensão e o processo formativo passa pela compreensão de que o movimento dialético, a historicidade e as mediações subsidiam o envolvimento dos pares, sua concepção em relação à extensão universitária e o processo avaliativo. Essas questões precisam ser pensadas considerando a contribuição da extensão para os processos de ensino e aprendizagem na universidade, as questões legais do processo de curricularização e as políticas da extensão, os contextos da extensão, a universidade e sua relação com a comunidade e a participação do estudante universitário nas práticas extensionistas. 


\section{Concepções da extensão universitária na formação do estudante}

Para este momento textual, objetivamos apresentar os diálogos teóricos em relação às concepções de extensão universitária no Brasil, que influenciam na elaboração e na efetivação das ações extensionistas e, por consequência, na formação de professores. As atividades de extensão no processo formativo do estudante devem ser compreendidas enquanto processos de ensino e aprendizagem, tal como no ensino e na pesquisa. O envolvimento do estudante nas atividades de extensão pode proporcionar momento de profissionalidade e, principalmente, de envolvimento com as questões sociais da realidade concreta na relação entre universidade e sociedade. Dessarte, é importante compreender qual a concepção da ação de extensão, pois, a partir dela, são organizadas as atividades que influenciam na formação do estudante.

Essa tessitura nos faz organizar os autores em seis categorias de análise, conforme Quadro 1. A primeira classifica a extensão mediante sua finalidade; a segunda, mediante sua atividade; a terceira, mediante suas características; a quarta, mediante seu sentido; a quinta, mediante suas perspectivas; e a sexta considera a epistemologia.

Quadro 1 - Categorias de concepção

\begin{tabular}{|c|c|c|}
\hline CATEGORIA & TEÓRICO & CONCEPÇÃO \\
\hline \multirow[t]{3}{*}{ FINALIDADE } & Jezine (2006) & * Assistencialista * Mercantilista * Acadêmica \\
\hline & González e Larrea (2006) & * Tradicional *Economicista * De desenvolvimento integral \\
\hline & Sousa (2000) & * Alienação * Emancipação \\
\hline ATIVIDADE & Silva (2000) & ${ }^{*}$ Tradicional ${ }^{*}$ Processual ${ }^{*}$ Crítica \\
\hline CARACTERÍSTICA & Reis (1996) & * Eventista-inorgânica *Processual-orgânica \\
\hline \multirow[t]{7}{*}{ SENTIDO } & Freire (1983) & * Humanização \\
\hline & Forproex (2012) & *Acadêmica \\
\hline & Síveres (2013) & *Aprendizagem \\
\hline & Gurgel (1986) & * Laboratório vivo \\
\hline & Botomé (1996) & * Indissociabilidade \\
\hline & Silva (2013) & ${ }^{*}$ Processo emancipatório \\
\hline & Melo Neto (2001) & * Trabalho social \\
\hline \multirow{3}{*}{ PERSPECTIVA } & Castro (2004) & * Transformação social \\
\hline & Thiollent (2002) & * Transformação do real \\
\hline & Jantke e Caro (2013) & * Emancipação \\
\hline EPISTEMOLOGIA & $\begin{array}{l}\text { Kochhann e Curado Silva } \\
\text { (2017) }\end{array}$ & ${ }^{*}$ Técnica * Prática * Práxis \\
\hline
\end{tabular}

Fonte: dados da pesquisa. 
A categorização nos leva à compreensão de que as ações de extensão podem apresentar como finalidade ou a prática do assistencialismo, o atendimento ao mercado e o atendimento à formação acadêmica, segundo Jezine (2006); ou a prática tradicional, economicista e de desenvolvimento integral, conforme González e Larrea (2006); ou ainda de alienação ou emancipação, na perspectiva de Sousa (2000). A discussão de Jezine (2004) mostra que o modelo assistencialista se configura por assessorias ou prestação de serviços, na área da educação, da agricultura e da saúde, às comunidades desfavorecidas, para a resolução de alguns problemas de ordem social, porém de forma imediata e paliativa. O modelo mercantilista abrange as ações que visam a favorecer o atendimento ao mercado, considerando as estruturas econômica e política vigentes no país como produtoras de bens e serviços. Já a extensão enquanto concepção acadêmica rompe com a barreira do pragmatismo, do ativismo, da fragmentação, da manipulação, da unilateralidade e reconhece o ser enquanto ser histórico, promovendo a consciência crítica e a transformação. Para González e Larrea (2006), a finalidade da concepção tradicional retoma a questão da universidade reprodutora e repassadora de conhecimento, que detém o saber e transmite-o à sociedade; enquanto a concepção economicista visa a atender as demandas do mercado capitalista; e a concepção do desenvolvimento integral apresenta a universidade aberta, criativa, democrática e crítica. Para Sousa (2000), sob uma perspectiva freireana, a extensão pode se apresentar enquanto atividades que promovam a emancipação e o desenvolvimento de capacidades humanas, enquanto prática transformadora do real, enquanto práxis revolucionária ou enquanto apenas mais um instrumento de alienação, primando por manter 0 status quo da instituição, enquanto fetichismo institucional.

Como atividades, as ações extensionistas podem apresentar a concepção tradicional, processual ou crítica, conforme discussão de Silva (2000). Para a autora, a atividade tradicional baseia-se no atendimento às carências sociais de forma apolítica, repassadora de conhecimento e assistencialista; já a atividade processual procura promover o compromisso social da instituição, quase como um atendimento mercadológico com produção técnica; e a concepção de extensão universitária como atividade crítica está imbricada no ensino e na pesquisa, configurando-se no currículo, promovendo a formação do acadêmico, que visa à transformação.

As ações extensionistas podem apresentar algumas características que denunciam se a extensão pertence à concepção eventista-inorgânica ou à processual-orgânica, conforme discute Reis (1996). As ações da linha conceitual eventista-inorgânica ocorrem eventualmente, ou seja, não têm uma continuidade, o que pode se aproximar dos conceitos de ações assistencialistas ou de intervenção, pois são eventos, cursos, palestras e outros. As ações processuais-orgânicas, ao contrário, 
são ações permanentes ou contínuas, que se relacionam de forma indissociável do ensino e da pesquisa, associando universidade e sociedade para a transformação.

Considerando a finalidade acadêmica de desenvolvimento integral, a atividade crítica e a característica processual-orgânica, as ações extensionistas devem vir a ser de humanização, acadêmicas, de aprendizagem: um laboratório vivo, indissociado da pesquisa e do ensino, e um processo emancipatório, conforme defendem Freire (1983), o Forproex (2012), Síveres (2013), Gurgel (1986), Botomé (1996) e Silva (2013). Freire (1983) entende que toda atividade deve levar o homem à humanização em seu sentido de consciência, amorosidade e respeito com o próximo, buscando a libertação da opressão. Segundo o Forproex (2012), as ações extensionistas devem ser um processo acadêmico, que ao longo da ação pode vir a favorecer a formação docente pela indissociabilidade com a pesquisa e o ensino, além disso, o desafio para a extensão universitária é garantir sua dimensão acadêmica como impacto na formação do estudante, abandonando a prática de ações isoladas, como a prestação de serviço. A agenda estratégica para a extensão universitária é reconhecer seu potencial formativo. Comungando do sentido acadêmico, Síveres (2013) discute que o sentido das ações extensionistas deve ser de aprendizagem, pois, não sendo uma prática desvinculada de teoria, como um mero ativismo pragmático, oportuniza uma gama de experiências de aprendizagem. Nessa linha de discussão, Gurgel (1986) defende que a extensão universitária tem o sentido de um verdadeiro laboratório vivo ou um campo de estágio vivo em um espaço real da prática social. Ainda, para Botomé (1996), a extensão universitária se relaciona com a pesquisa e o ensino, caso não ocorra essa indissociabilidade, a ação será equivoca em seu sentido. E Silva (2013) assevera que o sentido da ação extensionista é o processo emancipatório, que se constitui ao longo de uma caminhada contínua, em que o pensar e o agir extensionistas não estão dissociados.

Uma ação extensionista que abarque os elementos citados pode apresentar como perspectiva um trabalho social que promova a transformação social e a transformação do real e, quiçá, a emancipação, conforme defendem Melo Neto (2001), Castro (2004), Thiollent (2002) e Jantke e Caro (2013). Na perspectiva de Melo Neto (2001), as ações da extensão universitária podem ser biunívocas, devido ao trabalho que se realiza em uma realidade objetiva tendo como produto desse trabalho a cultura e o saber. Para Castro (2004), as ações extensionistas representam transformação social, por perceber a extensão como um espaço estratégico que promove variadas práticas que integram as diversas áreas do conhecimento. Thiollent (2002) assevera que a perspectiva das ações extensionistas pode ser de transformação social, considerando as dimensões participativa, crítica e emancipatória no coletivo e na prática social real, enquanto construção de uma sociedade que perceba 
o homem na sua totalidade. Com a mesma força, Jantke e Caro (2013) defendem que as perspectivas das ações extensionistas, tendo a práxis como articuladora da teoria e da prática, permitem desvendar os determinantes da realidade social em sua totalidade e alcançar a emancipação, se não humana, pelo menos acadêmica.

As ações extensionistas se expressam na realidade concreta conforme a epistemologia que as sustenta. Existem professores que organizam suas ações considerando a epistemologia da técnica, enquanto outros, da práxis, segundo Kochhann e Curado Silva (2017). A epistemologia da técnica valoriza as técnicas de ensino usadas para o momento da ação, voltadas para o tecnicismo, e a epistemologia da prática valoriza a prática da atividade, voltada para o praticismo; ambas dissociam a prática da teoria e, quiçá, da crítica. A epistemologia da práxis considera as questões históricas do movimento do real, estruturada a partir da unidade teoria e prática, objetivando, a partir das contradições, construir o conhecimento crítico e emancipado na relação entre os pares.

Com esse pano de fundo teórico, tomamos as concepções de extensão universitária no Brasil que influenciam na elaboração e na efetivação das ações extensionistas e, por consequência, na formação docente. Defendemos, assim, que: a finalidade seja acadêmica para desenvolvimento integral e emancipação; as atividades sejam desenvolvidas de forma crítica; as características das ações sejam processual-orgânicas; o sentido seja de humanização, acadêmico, de aprendizagem, de laboratório vivo, de indissociabilidade e de processo emancipatório; sua perspectiva seja de trabalho social, transformação social, transformação do real e emancipação; e a epistemologia seja da práxis.

\section{Curricularização da extensão universitária na formação do estudante}

Discutir a extensão universitária na formação do estudante passa por compreender as questões legais do processo de curricularização e políticas da extensão, visto que as atividades extensionistas serão elaboradas visando a atender as questões legalizadas. Nesse interim, primamos por apresentar as questões de curricularização da extensão mediante as discussões do PNE (BRASIL, 2001a, 2014), do PNEU (BRASIL, 2001b, 2011), do Forproex (2012) e de Reis (1996).

Em 1998, ocorreu o XIV Encontro Nacional dos Pró-Reitores de Extensão das Universidades Públicas Brasileiras, no qual se elaborou a proposta do Plano Nacional de Extensão. Esse plano, que deveria ser uma política, foi um documento que apresentou um avanço na concepção e no modelo de operacionalização da extensão universitária, pois defendeu uma concepção acadêmica para a extensão, em contraposição às atividades de prestação de serviços e assistencialismo. 
Em 2001, o PNE (2001-2010) foi lançado sob a Lei n. 10.172, com 285 metas, sendo que as metas 21, 22 e 23 tratam da extensão universitária. Segundo o PNE (BRASIL, 2001a), as instituições não devem ofertar cursos de extensão como prestação de serviços. Esses cursos devem ter características acadêmicas e primar por educação continuada:

21. Garantir, nas instituições de educação superior, a oferta de cursos de extensão, para atender as necessidades da educação continuada de adultos, com ou sem formação superior, na perspectiva de integrar o necessário esforço nacional de resgate da dívida social e educacional (BRASIL, 2001a, p. 38).

A meta 22 do PNE (BRASIL, 2001a) trata da criação de conselhos em que a comunidade civil deve participar e, inclusive, se posicionar em relação às questões da universidade, no caso especial, a indissociabilidade, em que garanta a via de mão dupla na relação sociedade e universidade.

22. Garantir a criação de conselhos com a participação da comunidade e de entidades da sociedade civil organizada, para acompanhamento e controle social das atividades universitárias, com o objetivo de assegurar o retomo a sociedade dos resultados das pesquisas, do ensino e da extensão (BRASIL, 2001a, p. 38).

Já a meta 23 do PNE (BRASIL, 2001a), a nosso ver, é a mais expressiva, visto propor que no mínimo $10 \%$ dos créditos exigidos nos cursos de graduação sejam obrigatoriamente cumpridos em ações extensionistas, de forma que o aluno atue em ações, não meramente receba ações. Isso denota que a ação extensionista não seja um mero evento e um mero curso, mas um projeto e/ou um programa, possibilitando a participação efetiva do acadêmico.

23. Implantar o Programa de Desenvolvimento da Extensão Universitária em todas as Instituições Federais de Ensino Superior no quadriênio 2001-2004 e assegurar que, no mínimo, $10 \%$ do total de créditos exigidos para a graduação no ensino superior no País será reservado para a atuação dos alunos em ações extensionistas (BRASIL, 2001a, p. 38).

Nossa hipótese é que essa meta pode não ter sido atingida no quadriênio estipulado nas instituições do ensino superior. Uma questão é o ensino superior ser composto por faculdades, centros, institutos e universidades, e a extensão ser obrigatória apenas para as universidades; assim, a meta deveria ser reescrita, substituindo o termo ensino superior pelo termo universidades. Da forma como está escrita, subentende-se que todas as instituições que ofertam ensino superior têm que implantar ações extensionistas. Outra questão é a abrangência do termo ações extensionistas, pois eventos, cursos, prestação de serviços, projetos e programas podem ser entendidos como ações extensionistas; mas essas atividades apresentam concepções e formas de envolvimento dos alunos distintas ${ }^{1}$. Essas questões são 
discutidas na próxima seção. Dessarte, a meta já demonstra um avanço em relação à extensão universitária no cenário da universidade, mas ainda apresenta pontos que precisam ser melhor discutidos, não sendo suficiente a legislação (FÁVERO, 1999).

É preciso uma mudança de concepção institucional envolvendo todo o corpo acadêmico. A obrigatoriedade da curricularização pode estar imposta por documentos, mas não ser entendida com

o essencial no processo de formação. Se não for entendida como processo formativo, as atividades de extensão podem não ser realizadas com a intensidade necessária e, quiçá, nem mesmo ser cumpridas.

É importante que sejam discutidos entre os pares das instituições a concepção, o sentido e a construção da extensão universitária mediante a legalização, para se pensar em como expressá-la no currículo e realizá-la de forma qualitativa, que beneficie a formação do acadêmico e a sociedade, pois "O potencial educativo e formativo da extensão deve ser inserido de modo qualificado no projeto pedagógico universitário" (SANTOS; DEUS, 2014, p. 12).

O PNE foi reforçado pelo PNEU, lançado na mesma época, em 2001. O PNEU (BRASIL, 2001b) foi elaborado pelo grupo de pró-reitores que defendiam mudanças de concepção, propondo o abandono do assistencialismo e da prestação de serviços, almejando uma concepção acadêmica que colocasse o aluno como partícipe fundamental mediante a ação na comunidade, vinculada aos saberes adquiridos nos momentos de ensino e pesquisa, sendo uma ação de dimensão processual, que ocorresse com certa temporalidade e sistematização, apresentando características de crítica da realidade concreta e não reprodução de conteúdos, conforme a concepção acadêmica apresentada pelo documento.

Esse tipo de extensão - que vai além de sua compreensão tradicional de disseminação de conhecimentos (cursos, conferências, seminários), prestação de serviços (assistências, assessorias e consultorias) e difusão cultural (realização de eventos ou produtos artísticos e culturais) - já apontava para uma concepção de universidade em que a relação com a população passava a ser encarada como a oxigenação necessária à vida acadêmica. A extensão, entendida como prática acadêmica que interliga a universidade nas suas atividades de ensino e de pesquisa com as demandas da maioria da população, possibilita essa formação do profissional cidadão e se credencia cada vez mais junto à sociedade como espaço privilegiado de produção do conhecimento significativo para a superação das desigualdades sociais existentes (BRASIL, 2001b, p. 4-8).

No tocante à institucionalização dessa nova concepção, vinculada ao processo de unidade teoria e prática, do pensar e do fazer universitários, pela sua importância acadêmica, são necessárias uma luta e a adoção de medidas e procedimentos, para garantir sua institucionalização; ou seja, não basta normatizar, é preciso que se concretize enquanto prática acadêmica. 
A Extensão é uma via de mão-dupla, com trânsito assegurado à comunidade acadêmica, que encontrará, na sociedade, a oportunidade de elaboração da práxis de um conhecimento acadêmico. No retorno à Universidade, docentes e discentes trarão um aprendizado que, submetido à reflexão teórica, será acrescido àquele conhecimento. Esse fluxo, que estabelece a troca de saberes sistematizados, acadêmico e popular, terá como conseqüências a produção do conhecimento resultante do confronto com a realidade brasileira e regional, a democratização do conhecimento acadêmico e a participação efetiva da comunidade na atuação da Universidade. Além de instrumentalizadora deste processo dialético de teoria/ prática, a Extensão é um trabalho interdisciplinar que favorece a visão integrada do social. Fica claro que a extensão só se concretizará, enquanto prática acadêmica, quando for discutida a sua proposta de ação global e sua inserção institucional nos departamentos, definindo as suas linhas de ensino e pesquisa em função das exigências da realidade (BRASIL, 2001b, p. 5-6).

O PNEU (BRASIL, 2001b), além de defender a extensão enquanto um processo de concepção acadêmica, apresenta um de seus princípios básicos: as atividades por vias da prestação de serviços, mas como um trabalho social visando à transformação social e de interesse acadêmico, articulado pelo ensino e pela pesquisa, reafirmando a extensão como processo acadêmico que promove formação tanto do aluno quanto do professor, por meio das atividades na sociedade.

a prestação de serviços deve ser produto de interesse acadêmico, científico, filosófico, tecnológico e artístico do ensino, pesquisa e extensão, devendo ser encarada como um trabalho social, ou seja, ação deliberada que se constitui a partir da realidade e sobre a realidade objetiva, produzindo conhecimentos que visem à transformação social; Reafirmar a extensão universitária como processo acadêmico definido e efetivado em função das exigências da realidade, indispensável na formação do aluno, na qualificação do professor e no intercâmbio com a sociedade (BRASIL, 2001b, p. 7-8).

Uma década se passou desde o PNE (2001-2010), e as questões de políticas educacionais visando à extensão universitária na concepção acadêmica pouco se expressam, apesar das metas 21, 22 e 23, que foram reformuladas para uma nova década. Das estratégias que o PNE (BRASIL, 2014, p. 74) apresentou quanto à meta 12, uma aborda a extensão universitária no tocante à obrigatoriedade curricular da experiência formativa em programas e projetos de extensão para todos os cursos e de todas as universidades.

12.7 assegurar, no mínimo, dez por cento do total de créditos curriculares exigidos para a graduação em programas e projetos de extensão universitária, orientando sua ação, prioritariamente, para áreas de grande pertinência social (BRASIL, 2014, p. 74).

Isso significa que todas as universidades, sejam públicas ou particulares, devem oferecer pelo menos 320 horas das 3.200 horas mínimas obrigatórias para as licenciaturas em programas ou projetos de extensão universitária. Portanto, cursos e eventos são atividades complementares e não créditos de extensão universitária. 
Já se passaram quase 4 anos desde o novo PNE, e provavelmente muitas instituições ainda não cumpriram com essa estratégia. Quiçá discutem sua curricularização. O PNE foi pensado para a melhoria da qualidade da educação brasileira em todos os níveis e modalidades, acreditamos que suas metas foram elaboradas nesse intuito, e suas estratégias, planejadas para alcançar esse objetivo. Fávero (1999) adverte que não basta criar normatizações, são necessários medidas e procedimentos que garantam sua efetividade.

Em 2011, foi lançado o novo Plano Nacional de Extensão Universitária pelo Forproex, reafirmando as questões do PNEU (BRASIL, 2001b) e a proposta de integração curricular pelas atividades de extensão universitária, que deve obrigatoriamente configurar os currículos dos cursos de graduação das universidades públicas. O PNEU (2011-2020), em sua meta 1, estabelece a curricularização da extensão universitária de, no mínimo, $10 \%$ da carga horária total do curso e especifica em cinco estratégias como alcançar a curricularização.

Meta 1: Incorporar até 2015 ao menos $10 \%$ do total de horas curriculares de formação acadêmica em programas e projetos de extensão fora dos espaços de sala de aula.

1.1) Estimular o reconhecimento da extensão em sua dimensão pedagógica e como elemento de construção do conhecimento no âmbito dos fóruns competentes;

1.2) Fomentar a criação de componentes curriculares em ações de extensão integradas aos currículos das formações em nível de graduação;

1.3) Reconhecer horas de integralização curricular pela atuação em projetos e programas de extensão;

1.4) Promover o exercício da indissociabilidade entre ensino, pesquisa e extensão de forma a assegurar a dimensão acadêmica da extensão na formação dos estudantes;

1.5) Criar mecanismos para reconhecimento dos espaços de extensão na condução de pesquisas (BRASIL, 2011, p. 2).

A meta 7, estratégia 7.2, do PNEU (2011), trata do financiamento da extensão e aborda a questão de bolsa tanto para docente quanto para acadêmicos, servidores e egressos: "Desenvolver bases legais que viabilizem a concessão de bolsas para professores, estudantes, servidores pós-graduandos e recém-formados de forma a estimular o desenvolvimento de ações de extensão articuladas ao ensino e à pesquisa" (BRASIL, 2011, p. 4).

A meta 10 do PNEU (2011) também chama a atenção, por estipular que até 2015 , nos projetos curriculares de todos os cursos, conste a extensão enquanto processo formativo, atendendo a determinados aspectos. 
Meta 10: Assegurar, até 2015, a incorporação nos projetos pedagógicos de todos os cursos de graduação (conforme previsto na grande maioria das diretrizes curriculares das áreas) o desenvolvimento, pela extensão, dos seguintes aspectos formativos: conhecimento da realidade nacional, pensamento crítico, cidadania ativa, trabalho em equipe, senso de solidariedade e justiça social (BRASIL, 2011, p. 4).

Sobre a curricularização da extensão universitária, Reis (1995) discute que é preciso pensar em elaboração dos currículos dos cursos das universidade considerando que são reflexo de seu tempo e de suas contradições. Assim, um currículo que expresse a intenção de formar os alunos com base na produção do conhecimento, pelas vias da indissociabilidade pesquisa, ensino e extensão, por uma contribuição de transformação e crítica, necessita de algumas mudanças nas concepções curricular e institucional.

1. Que o currículo se alicerçasse em um acordo político-pedagógico entre universidade e organismos da sociedade civil e política [...].

2. A necessidade de romper com a predominância da disciplina, como referência do currículo[...].

3. Que houvesse a reversão da dicotomia teoria-prática, hoje predominante na maioria dos cursos [...].

4. O currículo refletir a organização, o funcionamento, o planejamento e a ação articulada/articulante entre as várias instâncias decisórias da universidade [...].

5. Utilizar as prerrogativas do artigo 207 da Constituição brasileira, que garanta a autonomia da universidade, no seu ordenamento didático-pedagógico e de gestão [...].

6. Estabelecer uma rede de luta política entre pessoas e universidades diversas, se torna uma condição importante, para viabilizar o currículo, enquanto instrumento viabilizador do ensino/pesquisa/extensão [...].

7. Promover uma profunda reforma na legislação e nos currículos dos cursos das universidades (REIS, 1995 , p. 49-52).

O autor chama a atenção no sentido de que não adianta o PNE (BRASIL, 2001a, 2014), o PNEU (BRASIL, 2001b, 2011) e outros documentos oficializarem a obrigatoriedade da extensão, enquanto componente curricular, sem ocorrer uma mudança epistemológica nas concepções curricular e institucional, em que o pedagógico supere o político, o fim da supremacia disciplinar, o predomínio da unidade teoria-prática, a articulação entre as instâncias decisórias, a autonomia didático-pedagógico-financeira das instituições. A indissociabilidade pesquisa, ensino e extensão é de fato uma construção curricular com base nas novas concepções e nos 
novos sentidos. No final da década de 1990, seria uma reforma, chamamos hoje de revolução. Uma reforma apenas maquiaria a estrutura vigente e hegemônica. Uma revolução traria à tona uma nova estrutura curricular, de caráter contra-hegemônico em uma universidade emergente (SILVA, 2013).

A historicidade e a legalização da extensão universitária são muito marcadas pela prestação de serviços e pelo assistencialismo, sendo necessário um novo modo de compreender as atividades extensionistas - de forma acadêmica, processual e contínua em uma universidade emergente.

A prática histórica da extensão tem origem na concepção de universidade detentora do saber, único, verdadeiro, iluminado, que, por um lado, deveria ser transferido à população e, por outro, deveria ser colocado para assistir à [sic] população com o provimento de algum serviço. Esses modelos conceituais e institucionais receberam críticas e formulações de alternativas para o surgimento de uma extensão universitária mais engajada, dialogada e próxima da população excluída. As novas proposições pressupõem uma ação processual e contínua, não pontual, em que o conhecimento científico interaja com os demais saberes da população, em um diálogo permanente, visando à produção de conhecimentos e à apropriação para a resolução de problemas concretos das pessoas e de suas organizações (SILVA, 2013, p. 120).

Para tal, a história tem demonstrado por meio das políticas educacionais que as mudanças estão se apresentando viáveis às ações extensionistas de forma acadêmica, processual e contínua, as quais podem promover a aprendizagem.

Compreender a extensão universitária como um processo de aprendizagem reafirma o seu caráter acadêmico e viabiliza um percurso para que os projetos de ensino e de pesquisa revelem a possibilidade de um trabalho indissociável. Nesse sentido, o ensino, a pesquisa e a extensão configuram-se como atividades essenciais para garantir uma aprendizagem significativa com vistas à realidade contemporânea (SÍVERES, 2013, p. 31-32).

Sousa (2000) defende que a universidade precisa compreender a extensão como mediadora do conhecimento e de transformação das relações sociais, apesar de a história da universidade brasileira, por influência europeia e norte-americana, apresentar uma extensão não crítica e aculturada de uma forma alienada, que persiste ainda na atualidade. Contudo, desde o PNE (BRASIL, 2001a, 2014) e o PNEU (BRASIL, 2001b, 2011), a oficialização de uma nova concepção de extensão universitária vem ocorrendo. Isso denota que, se as concepções estão mudando, os sentidos e as construções de uma nova práxis extensionista devem existir, ou estão por vir a ser, como influenciadoras no processo de formação do estudante.

Em relação aos desafios e lutas de uma nova concepção de extensão universitária, o Forproex (2012) apresenta 13 desafios, e desses o terceiro chamou muito nossa atenção pela questão da expectativa de um paradigma contra-hegemônico, 
da dimensão acadêmica e do impacto na formação do estudante por vias da extensão universitária, visto que

A conjuntura atual, em geral favorável à expansão e consolidação da Extensão Universitária, é também desafiadora, na medida em que suscita expectativas de criação de paradigmas contra-hegemônicos que se primem pelo espírito colaborativo. Dentre os inúmeros desafios, destacam-se os seguintes: [...] 3. garantir a dimensão acadêmica da Extensão Universitária, isto é, seu impacto na formação do estudante, superando certa tradição de desenvolvimento de ações isoladas - particularmente na área de prestação de serviços - que têm carecido dessa dimensão (FORPROEX, 2012, p. 22, grifo do autor).

Essa nova concepção de extensão pode vir a ser o "[...] oxigênio de uma práxis revolucionária" (SOUSA, 2000, p. 129), afirmando que essa práxis é o papel da extensão na atualidade, sendo um instrumento transformador do real.

A práxis revolucionária é o fundamento e a finalidade do conhecimento; um conhecimento que o homem produz ao produzir as condições necessárias à sua existência, através do trabalho. O ponto de partida, portanto, para elaboração do conhecimento, são os homens, em sua atividade, em seu trabalho, no interior das relações sociais que eles geram (SOUSA, 2000, p. 130).

Dessa forma, a universidade brasileira deve ser compreendida enquanto promotora de aprendizagens em que a pesquisa, o ensino e a extensão são indissociáveis, cada qual com sua singularidade e complexidade inerentes aos processos contraditório e histórico, e contribuem para o processo de aprendizagem e de formação do estudante. Dessarte, consideramos importante um processo de acompanhamento e avaliação das atividades de extensão.

\section{Avaliação da extensão universitária na formação do estudante}

As ações de extensão universitária no processo formativo do estudante precisam ser acompanhadas e avaliadas, para, na contradição do movimento real, possibilitar uma formação crítica e emancipadora que transforme o social. Entre as várias mediações, trazemos à discussão proposições avaliativas na totalidade, defendidas pelo Forproex (2001), pelo Ofício Circular MEC/Sesu 263 (BRASIL, 1994 apud REIS, 1996) e por Reis (1995, 1996), desde o século passado e ainda atuais.

Para o Forproex (2001), o processo avaliativo é importante e deve considerar algumas dimensões: política de gestão, infraestrutura, relação universidade-sociedade, plano acadêmico e produção acadêmica. O objetivo das dimensões apresentadas pelo Forproex é "Auxiliar as Universidades a construir seus processos e metodologias de avaliação para extensão Universitária” (2001, p. 37). 
No tocante a compreender a política de gestão da instituição, a avaliação deve consistir em analisar as finalidades, os objetivos, o fomento, os conceitos, as metodologias, entre outras questões que os projetos apresentam, relacionando esses pontos à missão da instituição e à forma como esta percebe a extensão universitária.

A política de gestão contida nas finalidades, objetivos, fomento e atribuições da extensão, bem como seus instrumentos de ação, denunciam se a missão da universidade incorpora a função extensionista (FORPROEX, 2001, p. 50, grifo do autor).

Aliada à política de gestão está a dimensão infraestrutura, que precisa ser entendida como as condições básicas de efetivação de uma ação extensionista, no sentido de estruturas física e financeira, pois não basta um bom projeto idealizado, visto ser necessário que tenha condições de ser efetivado.

A dimensão infraestrutura informa sobre as condições físicas e gerenciais, reais, de realização da extensão e sobre as possibilidades de se consolidarem as metas almejadas; a relação universidade e sociedade revela de que modo as atividades de extensão estão presentes na sociedade, quais seus pressupostos e finalidades e como a universidade interage com a sociedade no sentido de transformações recíprocas (FORPROEX, 2001, p. 50, grifo do autor).

Considerando a política de gestão e a infraestrutura, é importante avaliar o plano acadêmico, pois, se a extensão universitária é um componente formativo, tanto quanto o ensino e a pesquisa, precisa desenvolver atividades que promovam a aprendizagem e experiências que possam ser validadas no currículo acadêmico.

O plano acadêmico analisa as possibilidades de incorporação da extensão na vida acadêmica, valorizando as experiências desenvolvidas pelo conjunto de participantes na ação extensionista (professores, funcionários e alunos) (FORPROEX, 2001, p. 50, grifo do autor).

Outro ponto que deve ser avaliado na ação extensionista é a produção acadêmica ou os produtos advindos das atividades extensionistas.

A produção acadêmica trata da captação dos produtos resultantes da ação da extensão, que elabora e dissemina conhecimentos e que, no âmbito universitário, tem o seu valor reconhecido (FORPROEX, 2001, p. 50, grifo do autor).

Considerando as dimensões da avaliação que o Forproex (2001) apresenta, reconhecendo os aspectos qualitativos, são apresentadas algumas categorias para a realização da avaliação de ações extensionistas.

Em relação à política de gestão, as categorias são: 1) política de extensão na instituição; 2) concepção de extensão; 3) órgãos colegiados de extensão; 4) resoluções e normas; 5) integração entre as ações da extensão e as da graduação, da pesquisa e da pós-graduação; 6 ) informatização dos dados e dos processos de operacionalização da extensão; e 7) sistema de acompanhamento e avaliação. 
Na dimensão infraestrutura, o aspecto qualitativo apresenta uma única categoria: estrutura administrativa, que contempla instalação, espaço físico, recursos humanos, transporte, equipamentos, entre outros.

$\mathrm{Na}$ relação entre universidade e sociedade, o aspecto qualitativo apresenta as seguintes categorias: 1) parcerias institucionais relativas à extensão; 2) clientela diretamente atendida pelas ações de extensão; 3) participação da comunidade na gestão da ação extensionista; 4) apropriação por parte da comunidade dos conhecimentos, tecnologias e metodologias desenvolvidos na ação extensionista; e 5) ação extensionista no redimensionamento da universidade.

No tocante à dimensão plano acadêmico, as categorias são: 1) interface ensino, pesquisa e extensão; 2) formas de aprovação, acompanhamento e avaliação das ações de extensão; 3) critérios para distribuição dos recursos aos programas, de acordo com a política de extensão; 4) formas de realização da extensão que indiquem o perfil das unidades acadêmicas e da instituição; e 5) extensão enquanto formação acadêmica.

$\mathrm{Na}$ dimensão produção acadêmica, o aspecto qualitativo não é mencionado, apenas uma categoria de aspecto quantitativo: quantificação da produção intelectual decorrente dos projetos de extensão em que deve aparecer o número de artigos publicados em periódicos, de livros editados, de comunicações em eventos, de publicações e relatórios com base nas ações extensionistas, além de outras publicações, como produção de vídeos, espetáculos, exposições, arranjos, etc.

Reis apresenta o Ofício Circular MEC/Sesu 263 (BRASIL, 1994 apud REIS, 1996), que oficializou a concepção orgânico-processual a partir de alguns critérios: relevância acadêmica, relevância social, viabilidade social, compromisso institucional e possíveis decorrências nas instituições, apresentando subsídios concretos para a transformação do real. Mas só isso não basta. São necessárias compreensão dessa concepção e ação da comunidade acadêmica. Esses critérios podem ser percebidos nos documentos do Forproex $(2001,2012)$. Nossa pesquisa se alicerça em alguns desses critérios, principalmente o critério da relevância acadêmica. Mas esse critério não pode ser considerado isolado dos demais, visto que o compromisso institucional e as possíveis decorrências nas instituições podem influenciar na relevância acadêmica. Portanto, os critérios se tornam indissociáveis, de forma dialética e contraditória.

A relevância acadêmica se apresenta pela indissociabilidade entre a pesquisa, o ensino e a extensão, bem como pelo processo interdisciplinar e pelo envolvimento dos acadêmicos nas ações. Essas questões também compõem as categorias que elegemos a priori para nossas análises. 
- Proposta globalizante e orgânica na articulação do ensino/pesquisa/extensão onde estejam inter-relacionados conteúdos de disciplinas, concepções de pesquisa e demandas da sociedade. - Interdisciplinaridade: entendida como inter-relação de competência e complementaridade entre as áreas do conhecimento. - Grau e forma de participação dos diversos sujeitos da comunidade acadêmica (REIS, 1996, p. 44).

Considerando de forma permanente essa proposta globalizante e orgânica nas ações extensionistas, as possibilidades de ocorrer uma práxis crítico-emancipadora que pode propiciar condições de transformação social, além das condições reais de formação acadêmica, são grandes, pois as atividades de extensão são realizadas em vários espaços, não somente na instituição.

A relevância não pode ser apenas para o acadêmico, mas também para a sociedade. Por isso é importante o envolvimento da sociedade nas ações, vinculada a um problema real e necessário, com possibilidade de mudanças, inclusive com implementação de tecnologias desenvolvidas pelos acadêmicos para amenizar ou sanar a problemática social. Assim, a relevância social ficou estabelecida como princípio para uma ação extensionista.

- Grau e forma de participação da sociedade: possibilidade da repercussão social da temática. - Problemática abordada: possibilidade de contribuição para a inserção política, econômica, social e cultural da população excluída. - Possibilidade de criação, desenvolvimento e difusão de tecnologias apropriadas (REIS, 1996, p. 44).

As relevâncias acadêmica e social demonstram que as ações extensionistas são de extrema importância, pois contribuem diretamente para as mudanças na sociedade, empoderando seus sujeitos. Mas, para a possibilidade de relevâncias acadêmica e social, as ações precisam ser viáveis, importantes, financiáveis e exequíveis. A viabilidade social ficou estabelecida, segundo Reis, como: “- Compatibilidade entre os objetivos do programa e os mecanismos de operacionalização propostos. - Definição das etapas de implantação, execução e avaliação" (1996, p. 44).

Dessarte, as relevâncias acadêmica e social e a viabilidade social perpassam pelo compromisso que a instituição irá demandar para a ação, no tocante ao financiamento, a permanência da ação, a disponibilidade de pessoal para a realização da ação, entre outras questões. O compromisso institucional ficou estabelecido, segundo Reis, como: “- Relação com o plano de trabalho das IES. - Aprovação nas instâncias de deliberação acadêmica das IES. - Recursos investidos pela IES, como contrapartida. - Garantia de continuidade" (1996, p. 44). Para o autor, as ações extensionistas são planejadas e efetivadas mediante os documentos legais. Assim, sua institucionalização se efetiva de forma escrita, sendo necessária uma análise de como se efetiva na realidade concreta e com qual concepção. 
Apesar de apontar que a concepção processual-orgânica das ações extensionistas apresenta relevâncias acadêmica e social bem como viabilidade social e compromisso institucional, o último critério do Ofício Circular MEC/Sesu 263 apresenta a possibilidade de a concepção orgânico-processual sofrer alguns problemas para sua efetivação devido a possíveis decorrências nas instituições (BRASIL, 1994 apud REIS, 1996).

Apesar de o ofício circular apresentar quatro critérios favoráveis a ações extensionistas processual-orgânicas, mostra como último critério a possibilidade de existir decorrências nas instituições de ensino superior (IES), e isso ser uma dificuldade de maior ou menor grau, dependendo de vários elementos constitutivos da instituição. Assim, cabe analisar essas possíveis decorrências. Uma das decorrências nas IES levantadas quanto a concepção processual-orgânica é no tocante à definição política-filosófica da universidade, pois é preciso pensar se a instituição formadora almeja a manutenção do status quo ou a superação da realidade concreta, via ensino, pesquisa e extensão. Essa questão precisa ser analisada hoje nas instituições, para poder compreender a forma de estabelecimento das ações extensionistas.

Outra decorrência levantada foi quanto a democratização e a redistribuição do poder da universidade, pois é preciso viabilizar o acesso da sociedade civil à universidade, bem como ampliar a participação de técnicos e principalmente de acadêmicos, porque o poder se estabelece basicamente nas mãos dos docentes, mas, para que haja um aprendizado, é necessária a distribuição igualitária do poder, favorecendo que a extensão represente e possibilite a indissociabilidade com o ensino e a pesquisa, atendendo "demandas e necessidades da sociedade como um todo" (REIS, 1996, p. 44).

Outra ponto é o sentido que a instituição atribui às ações extensionistas, pois, se elas visam a reverter a miséria e a pobreza do país, é preciso construir um projeto exequível, contínuo e crítico em parceira com a sociedade civil, visando a "[...] uma ação organicamente articulada nos interesses e [à] construção da perspectiva de uma nova sociedade" (REIS, 1996, p. 44).

Outra questão é perceber se as IES assumem a relação teoria-prática como pressuposto do processo ensino-aprendizagem. Para tal, a análise deve ser no sentido de que as IES precisam romper com o teoricismo, retórica e crítica cômodas, como apresenta Reis: "[...] mergulhar no real concreto com suas contradições numa perspectiva de contribuição transformante" (1996, p. 44). Esse critério deve ser compreendido como unidade teoria-prática visando à transformação consciente da realidade concreta, pois "Teorizar sim, mas simultânea a uma prática de contribuição transformadora. Agir sim, com teorização concomitante. Enfim, desenvolver 
uma ação, num movimento de permanente reflexão e simultaneamente oxigenante da própria ação" (REIS, 1996, p. 44).

Outro item é redimensionar conteúdos curriculares, relacionando universidade e sociedade, realizando a aproximação com o concreto enquanto eixo dorsal. Para isso, é importante a participação da sociedade civil no planejamento participativo da universidade, "nestes articular-se-iam conteúdos de disciplinas e departamentos e cursos, balizados nos interesses comuns acordados entre a universidade e a população" (REIS, 1996, p. 45).

Outra questão é modificar o conceito de aula e sala de aula, pois a extensão universitária rompe com as barreiras e os espaços físicos da sala de aula e do modelo tradicional de ensino, alcançando todos os locais e situações que envolvem a reciprocidade entre universidade e sociedade.

Outro ponto é, segundo Reis, "modificar o conceito de currículo e sua decorrente operacionalização" (1996, p. 46, grifo do autor), pois o currículo, elaborado de forma democrática e participativa, leva em consideração as demandas sociais, levantadas pela própria sociedade. Para isso, outro item é a articulação das variadas instâncias gestoras e decisórias da universidade, no sentido de compreender a importância da gestão democrática e participativa, rompendo com o estanquismo e o isolamento das decisões.

Nesse cenário, estão os financiamentos das ações extensionistas, pois a alocação orçamentária das IES precisa ser equilibrada em relação a ensino, pesquisa e extensão. Para isso, é preciso uma decisão político-orçamentária, que financie as ações extensionistas de forma que garanta sua realização com a equivalência do ensino e da pesquisa, inclusive com alocação de carga horária.

O que se pretende é que a carga horária contemple em sua concepção acadêmica-administrativa a articulação ensino, pesquisa, extensão e administração. Ou seja, o ato de relação com a sociedade inerente tenha base no processo formativo, na produção do conhecimento e na ação administrativa (REIS, 1996, p. 46).

Sousa argumenta que "A concepção e institucionalização da Extensão são temas que trazem consigo o problema do financiamento. Estas são as questões fundamentais sobre as atividades extensionistas" (2000, p. 101). A autora ainda discute que, quando a questão é o financiamento da extensão, os órgãos competentes abordam o problema da distribuição dos recursos alegando que são poucos para atingir o ensino, a pesquisa e a extensão.

Outro ponto é o fato de as IES valorizarem à questão da diversidade, estabelecendo-a como objetivo. 
A construção do ensino, pesquisa, extensão na convivência com o diferente, na diferença e com amor [...]. O diferente é o que instiga, complementa, convida a caminhar, avançar, a buscar a superação de cada situação. Esta superação (humano-dialética) é a esperança da superação das dificuldades econômicas-políticas-culturais-sociais, que cada brasileiro vive, cada cidadão enfrenta e se constitui em desafio a toda humanidade (REIS, 1996, p. 46)

As questões que Reis (1996) discute em relação ao ofício circular devem ser consideradas ao analisar pontos de efetivação de ações extensionistas na atualidade, pois os critérios, apesar de elaborados no século passado, são muito atuais e, quiçá, ainda predominam nas universidades.

Para o autor, ao avaliar um programa ou um projeto de extensão, são necessários: a) considerar a situação dos contextos internacional e nacional-local, para elaborar uma ação extensionista com base na realidade concreta; b) avaliar a pesquisa, o ensino e a extensão de maneira orgânica e simultânea e não de forma linear e fragmentada, percebendo no movimento a indissociabilidade; c) perceber a que interesses político-ideológicos a ação serve, se para a formação docente ou o atendimento ao mercado neoliberal; d) analisar o processo democrático do poder da universidade, pois, muitas vezes, ocorre a concentração de decisão nas mãos de alguns gestores que podem estar distantes da realidade concreta; e) emergir os conteúdos e interesses político-ideológicos que a ação está veiculando para pensar na metodologia e na produção acadêmicas da ação; f) perceber a articulação entre as instâncias decisórias da universidade, visto que as decisões não podem ser por grupos que não dominam os conceitos e estão distantes da realidade concreta; g) analisar o conceito de sala de aula e aula da ação, primando pelo rompimento com o tradicionalismo e pela linearidade do trabalho pedagógico; h) compreender como se dá a relação/unidade teoria e prática na ação, se ocorre a dissociação, em que a teoria não chega à prática e vice e versa, sendo apenas um teoricismo e um praticismo; e i) avaliar a prestação de contas da ação à comunidade com a divulgação dos dados e resultados, podendo ser com as publicações das variadas formas. Reis (1996) assevera que, considerando essas proposições avaliativas, é possível identificar a concepção de extensão que a ação carrega.

A discussão sobre avaliação das ações extensionistas se torna importante no contexto de alguns diálogos teóricos sobre concepção extensionista, justamente para compreender, no processo da unidade teoria e prática, como se configura a atividade e qual a concepção que emerge dessa compreensão, pensando que a ação pode vir a ter continuidade precisa, organicamente ser replanejada para, de forma sistemática, corrigir os equívocos da ação.

As dimensões e categorias do Forproex (2012) e as dimensões elencadas por Reis (1996) podem ser consideradas no processo avaliativo, para fomentar a compreensão e a construção de concepções em relação à extensão universitária, que 
precisa ser colocada em análise, na contradição, na totalidade e nas mediações, possibilitando um (re)pensar no tocante ao papel da extensão universitária nos cenários acadêmico e social.

Parte-se do pressuposto que a extensão universitária parece se constituir em uma atividade acadêmica que expressa sua importância na capacidade de imprimir um novo rumo à universidade brasileira, o que traz à luz diferentes contribuições significativas acerca de como as mudanças estruturais podem acontecer na sociedade. Por essa mesma razão, a política de formação profissional ganha destaque, principalmente no que diz respeito à responsabilidade de formar profissionais comprometidos com os processos de transformação da sociedade (DEUS; HENRIQUES, 2017, p. 81).

Eis alguns diálogos teóricos que intentamos despertar e apresentar enquanto possibilidades na formação docente, visto que a extensão universitária tem sua legalização ao lado da pesquisa e do ensino, como atividades formativas, que se apresentam no limbo de variados espaços formativos na/da/para a prática social em uma realidade concreta com problemas reais, de pessoas reais, mediante um movimento dialético e contraditório, inserido em um cenário histórico que carrega toda questão política e econômica. Com essa tessitura, a formação docente se daria na forma mais real e concreta, em que a teoria e a prática de fato podem vir a ser unidade, visando a uma formação crítica e emancipadora, para propiciar transformações sociais de forma mediata.

\section{Considerações}

Como o objetivo deste trabalho foi apresentar as concepções de extensão universitária no Brasil, que influenciam na elaboração e na efetivação das ações extensionistas e, por consequência, na formação dos estudantes, relacionamo-las com a questão da curricularização e o processo avaliativo das atividades, por julgarmos que as ações podem ser modificadas em sua concepção pela avaliação.

Entendemos que a formação do estudante sofre influência das ações extensionistas enquanto variados espaços formativos, tanto na formação inicial quanto na continuada. $\mathrm{O}$ que caracteriza essa influência, com base em nossas análises, são a finalidade, a atividade, a característica, o sentido, a perspectiva e a epistemologia que a ação extensionista carrega em si, mediante as contradições, a totalidade e as mediações na relação entre o pensar e o fazer. Dessarte, as questões de curricularização e o processo avaliativo se tornam importantes para compreender como a ação ocorre em seu processo de pensar e fazer, repensar e refazer, visto que a ação se apresenta em constante movimento. 
Nesse limbo, a tessitura entre as atividades de extensão e o processo formativo passa por compreender que as atividades de extensão não podem ser de prestação de serviços e assistencialismo, mas de ordem acadêmica, visando à transformação do real. A participação nos projetos e programas de extensão deve ser no currículo do estudante de no mínimo $10 \%$ dos créditos totais do curso, enquanto um processo indissociável da pesquisa e do ensino. $\mathrm{O}$ acompanhamento e a avaliação das ações extensionistas devem ocorrer seguindo os critérios do Forproex, primando por indissociabilidade, interdisciplinaridade, interprofissionalidade, produção acadêmica, dialogicidade, transformação social e impacto na formação do estudante.

\section{Nota}

1 Neste trabalho, usaremos os termos “ações" e "projetos" justamente para demarcar a divergência conceitual.

\section{Referências}

BOTOMÉ, Silvio Paulo. Pesquisa alienada e ensino alienante: o equívoco da extensão universitária. São Paulo: Vozes, 1996.

BRASIL. Plano Nacional de Extensão Universitária. 2011. Disponível em: <https://www2.ufmg. br/proex/content/download/7042/45561/file/PNEU.pdf>. Acesso em: 16 maio 2018.

. Plano Nacional de Educação. 2001a. Disponível em: <http://portal.mec.gov.br/arquivos/ pdf/L10172.pdf>. Acesso em: 16 maio 2018.

Plano Nacional de Extensão Universitária. 2001b. Disponível em: <http://portal.ufpa. br/imagens/docsq/Trasparencia_publica/legislacao/Planonacionaldeexyensaouniversitaria.pdf $>$. Acesso em: 12 maio 2018.

Plano Nacional de Educação. 2014. Disponível em: <http://pne.mec.gov.br/imagens/pdf/ pne_conhecendo_20_metas.pdf>. Acesso em: 19 maio 2018.

CASTRO, Luciana Maria Cerqueira. A universidade, a extensão universitária e a produção do conhecimentos emancipadores. In: Reunião Anual da ANEPD, 27, Caxambu/MG. Anais... Caxambu, 2004.

DEUS, Sandra; HENRIQUES, Regina Lucia Monteiro. A universidade brasileira e sua inserção social. In: CASTRO, Jorge Orlando; TOMMASINO, Humberto (Org.) Los caminos de la extensión en América Latina y el Caribe. Santa Rosa: Universidad Nacional de La Pampa, 2017. p. 77-92.

FÁVERO, Maria de Lourdes. Universidade, espaço da pesquisa e da criação do saber. Educação e Filosofia, Uberlândia, MG, v. 13, n. 25, p. 249-259, jan./jun. 1999.

FORPROEX. Avaliação Nacional da extensão Universitária. 2001. Disponível em: <.https://www. ufmg.br/proex/renex/index.php/documentos>. Acesso em: 22 maio 2018. 
. Fórum Pró-Reitores de Extensão das Universidades Públicas Brasileiras. 2012. Disponível em: <http:/www.utfpr.edu.br/estrutura-universitaria/pro-reitorias/prorec/diretoria-de-extensao/documentos-da-extensao-de-ambito-nacional/politica-nacional-de-extensao-universitaria-forproex-2012/view>. Acesso em: 25 maio 2018.

FREIRE, Paulo. Extensão ou comunicação? Tradução de Rosisca Darcy de Oliveira. Prefácio de Jacques Chonchol. 7. ed. Rio de Janeiro: Paz e Terra, 1983.

GONZÁLEZ, Gil Ramón González; LARREA, Mercedez González Fernández. Gestión de la Extensión universitária: uma aproximación conceptual desde la perspectiva cubana. Revista Cubana de Educación Superior, Havana, Cuba, v. XXII, n. 2, p. 55-68, 2002. Disponível em: <https:// dialnet.unirioja.es/ejemplar/173813>. Acesso em: 23 nov. 2017.

GURGEL, Roberto Mauro. Extensão universitária: comunicação ou domesticação. São Paulo: Cortez, 1986.

JANTKE, Regina Vazquez Del Rio; CARO, Sueli Maria Pessagno. A Extensão e o exercício da cidadania. In: SÍVERES, Luiz (Org.). A extensão universitária como princípio de aprendizagem. Brasília: Liber, 2013. p. 97-108. Disponível em: <http://unesdoc.unesco.org/ images/0023/002320/232083por.pdf>. Acesso em: 20 jun. 2016.

JEZINE, Edineide Mesquita. As práticas curriculares e a extensão universitária. In: CONGRESSO BRASILEIRO DE EXTENSÃO UNIVERSITÁRIA, 2. 2004, Belo Horizonte. Anais... Belo Horizonte, 2004. p. 1-6. Disponível em: <https://www.ufmg.br/congrext/Gestao/Gestao12.pdf>. Acesso em: 25 nov. 2016.

JEZINE, Edineide Mesquita. A crise da universidade e o compromisso social da extensão universitária. João Pessoa: UFPB, 2006.

KOCHHANN, Andréa; CURADO SILVA, Kátia Augusta Cordeiro Pinheiro. Formação docente e extensão universitária: concepções, sentidos e perspectivas. In: REIS, Marlene Barbosa de Freitas; LUTERMAN, Luana Alves. Interdisciplinaridade na Educação: redimensionando práticas pedagógicas. Anápolis: UEG, 2017. p. 107-124.

MELO NETO, José Francisco. Extensão universitária: uma análise crítica. João Pessoa: Editora Universitária, 2001. Disponível em: <http://www.prac.ufpb.br/copac/extelar/producao_academica/livros/pa_l_2001_extensao_universitaria_-_uma_analise_critica.pdf>.Acesso em: 18 jul. 2016.

REIS, Renato Hilário dos. Extensão universitária: conceituação e práxis. In: FÓRUM DE EXTENSÃO DA UDESC, 1., 1993, Florianópolis. Anais... Florianópolis: UDESC, 1993. p. 17-23.

REIS, Renato Hilário dos. O currículo enquanto instrumento viabilizador da articulação Ensino, Pesquisa e Extensão. Cadernos de Extensão Universitária, Universidade Federal do Espírito Santo, Espírito Santo, a. 1, n. 4, p. 42-58, 1995.

REIS, Renato Hilário dos. Histórico, tipologias e proposições sobre a extensão universitária no Brasil. Linhas Críticas, Brasília, v. 2, n. 2, p. 41-47, 1996. Disponível em: <http://periodicos.unb. br/index.php/linhascriticas/article/download/6094/5042>. Acesso em: 15 jun. 2016.

SANTOS, José Antônio; DEUS, Sandra. Um novo tempo da extensão universitária brasileira. Interfaces Revista De Extensão, Belo Horizonte, v. 2, n. 2, p. 6-16, jan./jun. 2014. 
SILVA, Maria das Graças. Universidade e sociedade: cenários da extensão universitária? In: REUNIÃO ANUAL DA ANPED, 23., 2000, Rio de Janeiro. Anais... Rio de Janeiro, 2000, Não paginado. Disponível em: <http://www.anped11.uerj.br/23/1101t.htm>. Acesso em: 24 set. 2016.

SILVA, Enio Waldir da. Fortalecendo a cultura cidadã dos estudantes - um dos papéis da extensão na universidade. In: SÍVERES, Luiz (Org.). A extensão universitária como princípio de aprendizagem. Brasília: Liber, 2013. p. 109-136. Disponível em: <http://unesdoc.unesco.org/ images/0023/002320/232083por.pdf>. Acesso em: 20 jun. 2016.

SÍVERES, Luiz. O princípio da aprendizagem na extensão universitária. In: SÍVERES, Luiz (Org.). A extensão universitária como princípio de aprendizagem. Brasília: Liber, 2013. p. 19-36. Disponível em: <http://unesdoc.unesco.org/images/0023/002320/232083por.pdf>. Acesso em: 20 jun. 2016.

SOUSA, Ana Luiza Lima. A história da extensão universitária. Campinas: Alínea, 2000.

THIOLLENT, Michel. Construção do conhecimento e metodologia da extensão. In: CONGRESSO BRASILEIRO DE EXTENSÃO UNIVERSITÁRIA, 1., 2002, João Pessoa. Anais... João Pessoa, 2002. p. 1-11. Disponível em: <http://www.prac.ufpb.br/anais/Icbeu_anais/anais/conferencias/ construcao.pdf>. Acesso em: 21 jun. 2016. 